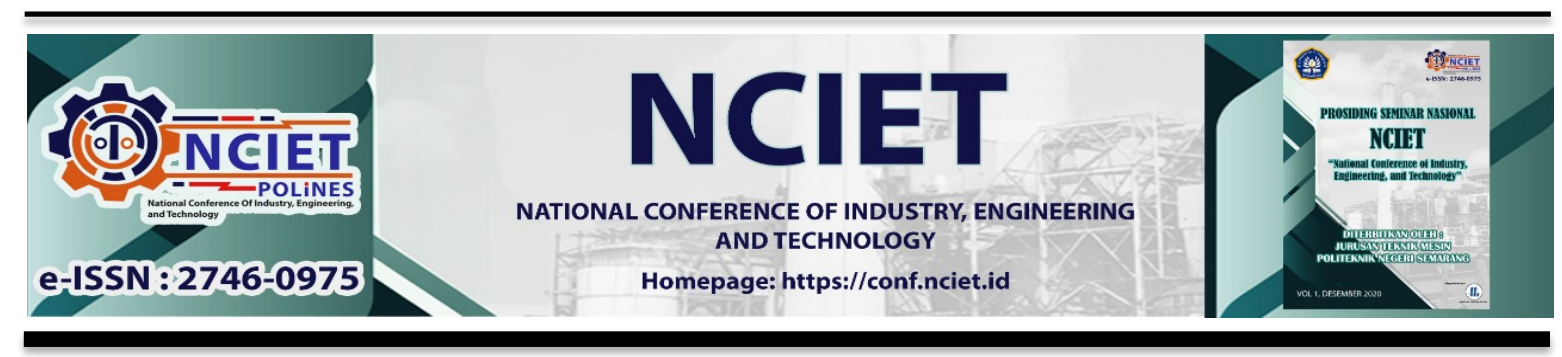

Prosiding Seminar Nasional NCIET Vol.1 (2020) B475-B486

$1^{\text {st }}$ National Conference of Industry, Engineering and Technology 2020,

Semarang, Indonesia.

\title{
PERANCANGAN ECONOMIZER TIPE HELICAL FIN AND TUBE PADA SISTEM BOILER KAPASITAS 115 TON/H
}

\author{
Muhammad Reza Putra*, Kholiq Hernawan, Annisa Syafitri K \\ Teknik Konversi Energi, Politeknik Negeri Bandung \\ Jl. Gegerkalong Hilir, Ds. Ciwaruga, Kec. Parongpong, Kab. Bandung Barat, 40559 \\ *E-mail: mreza.putra23@gmail.com
}

\begin{abstract}
Abstrak
Industri minyak bumi merupakan salah satu industri yang menggunakan energi listrik sebagai faktor penting dalam proses produksinya. Salah satu alat yang memiliki peran penting dalam menunjang pembangkitan energi listrik yaitu boiler. Boiler merupakan bagian penting dari Utilities Section yang menghasilkan steam untuk menggerakan turbin. Untuk menghasilkan steam, boiler menggunakan natural gas dan solar sebagai bahan bakar. Konsumsi bahan bakar yang tinggi dengan jumlah steam yang dihasilkan relatif tetap akan berdampak pada kinerja boiler dan biaya konsumsi energi yang tinggi. Oleh karena itu perlu dilakukannya langkah koservasi energi dengan meggunakan economizer. Temperatur keluraran flue gas boiler sebesar $654.404^{\circ} \mathrm{C}$ dapat dimanfaatkan untuk memanaskan feed water. Penggunaan economizer tipe helical fin and tube dapat meningkatkan efisiensi boiler dari $93.65 \%$ menjadi $94.4 \%$. Hasil rancangan economizer tipe helical fin and tube ini lebih efisien dari tipe bare tube karena memiliki luas perpindahan panas yang lebih besar hal ini dibuktikan dengan efektivitas perancangan yang meningkat yang sebelumnya sebesar 0.243 menjadi 0.402 .
\end{abstract}

Kata Kunci: economizer; helical fin and tube; heat exchanger; efisiensi boiler; efektivitas

\section{PENDAHULUAN}

Peranan energi dalam berbagai sektor sebagai penunjang kehidupan manusia sangat penting dilakukan pengoptimalan dalam hal penggunaanya. Menurut Direktorat Jenderal Energi Baru Terbarukan dan Konservasi Energi (EBTKE), terdapat sektor-sektor yang berperan sebagai pengonsumsi energi utama yaitu sektor industri, sektor komersial, sektor transportasi, dan sektor rumah tangga. Sektor industri merupakan pengonsumsi energi akhir terbesar karena fungsi energi itu sendiri yaitu sebagai bahan bakar untuk penunjang proses produksi dan dipakai untuk bahan baku produk sehingga perlu dilakukannya pengoptimalan penggunaan energi.

Salah satu industri yang menggunakan energi sebagai faktor penting dalam proses produksinya yaitu industri minyak bumi. Dengan adanya perkembangan ilmu pengetahuan dan teknologi serta kebutuhan hidup yang terus meningkat maka tentunya akan semakin 
meningkat pula kebutuhan akan sumber energi khususnya sumber energi yang berasal dari Bahan Bakar Minyak (BBM).

\section{Sektor Pengonsumsi Energi}

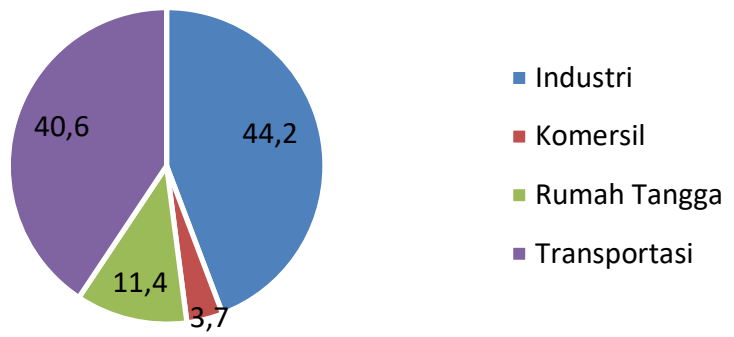

Gambar 1. Sektor Pengonsumsi Energi di Indonesia Sumber: Dirjen EBTKE, Tahun 2016

Sumber daya alam Indonesia berupa minyak bumi diolah oleh PT Pertamina (Persero) yang terdapat dalam unit pengolahan (Refinery Unit). Refinery Unit merupakan salah satu refinery yang menghasilkan berbagai macam produk minyak dan dalam menunjang produksi tersebut didukung oleh Utilities Section. Unit tersebut merupakan bagian terpenting dari produksi, karena unit tersebut memproduksi listrik sebagai suplai energi utama produksi, mengolah limbah, serta produksi gas nitrogen untuk menunjang produksi dan masalah keamanan.

Peralatan penunjang operasi yang menyangkut pengolahan seluruh kebutuhan kilang kesemuanya berada di unit Utilitas, yang salah satu fungsinya menyediakan steam/uap yang dihasilkan oleh boiler. Untuk menjaga atau meningkatkan kinerja boiler perlu dilakukannya langkah konservasi energi. Konservasi energi yang dapat dilakukan yaitu dengan meminimalkan heat loss yang dihasilkan oleh boiler. Menurut buku How to Save Energy and Money in Boilers and Furnace Systems, terdapat beberapa cara untuk meminimalkan heat loss pada boiler yaitu perawatan, mengurangi blowdown heat loss, mengurangi heat transfer yang tidak diinginkan, mengurungi heat loss dari radiasi, mereduksi excess air, flue gas heat recovery, air pre-heat pada sistem pembakaran, dan penjadwalan beban.

Heat loss yang besar pada boiler berada pada flue gas yang dihasilkan. Flue gas merupakan gas hasil sisa pembakaran yang terbuang ke udara melalui stack boiler. Temperatur flue gas yang masih tinggi dapat dimanfaatkan kembali untuk memanaskan feed water. Dengan meningkatnya temperatur feed water maka efisiensi boiler akan meningkat 
karena adanya pengurangan jumlah bahan bakar yang digunakan pada boiler. Salah satu cara untuk memanfaatkan panas dari flue gas yaitu dengan memasang economizer tipe helical fin and tube pada stack boiler. Keadaan eksisting economizer sebelumnya tidak memiliki fin atau economizer tipe bare tube. Fin dengan tipe helical pada tube economizer akan membantu memperluas bidang penyerapan panas sehingga panas yang berpindah dari flue gas ke feed water akan maksimal terutama pada boiler yang berbahan bakar natural gas. Kelebihan dari helical fin pada tube ini yaitu cocok digunakan untuk flue gas yang berasal dari bahan bakar natural gas dan hasil olahan minyak bumi (solar) selain itu juga helical fin tersusun secara kontinyu sehingga panas yang diserap pun lebih efektif dibandingkan dengan plate fin atau longitudinal fin (Rayaprolu, 2009).

\section{METODE PENELITIAN}

Perancangan economizer tipe helical fin tube ini memerlukan studi literatur baik itu dari buku, jurnal ilmiah, dan perusahaan lain yang sudah menerapkan konservasi energi pada boiler dengan menggunakan economizer. Selanjutnya perlu dilakukannya pengambilan data operasi atau existing pada boiler dan menentukan parameter awal perancangan economizer dari sisi tube maupun sisi shell. Audit energi berfungsi untuk mengetahui nilai efisiensi boiler sehingga dapat dipilih data yang akan digunakan untuk perancangan. Setelah audit energi pada boiler dilakukan simulasi data eksisting dengan menggunakan software HTRI yang hasilnya didapatkan panas spesifik, temperatur keluaran dari flue gas dan feed water, serta luas perpindahan panas. Temperatur keluaran feed water dan flue gas selanjutnya digunakan untuk perhitungan perancangan economizer tipe helical fin and tube. Validasi perhitungan hasil perancangan menggunakan simulasi software HTRI. Parameter proses dan geometri perancangan dimasukan ke dalam HTRI. Hasil dari simulasi dibandingkan dengan perhitungan perancangan. Setelah dilakukan validasi, perancangan economizer tipe helical fin and tube digambar dengan menggunakan software SolidWorks dengan parameter geometri yang di dapat sebelumnya. 


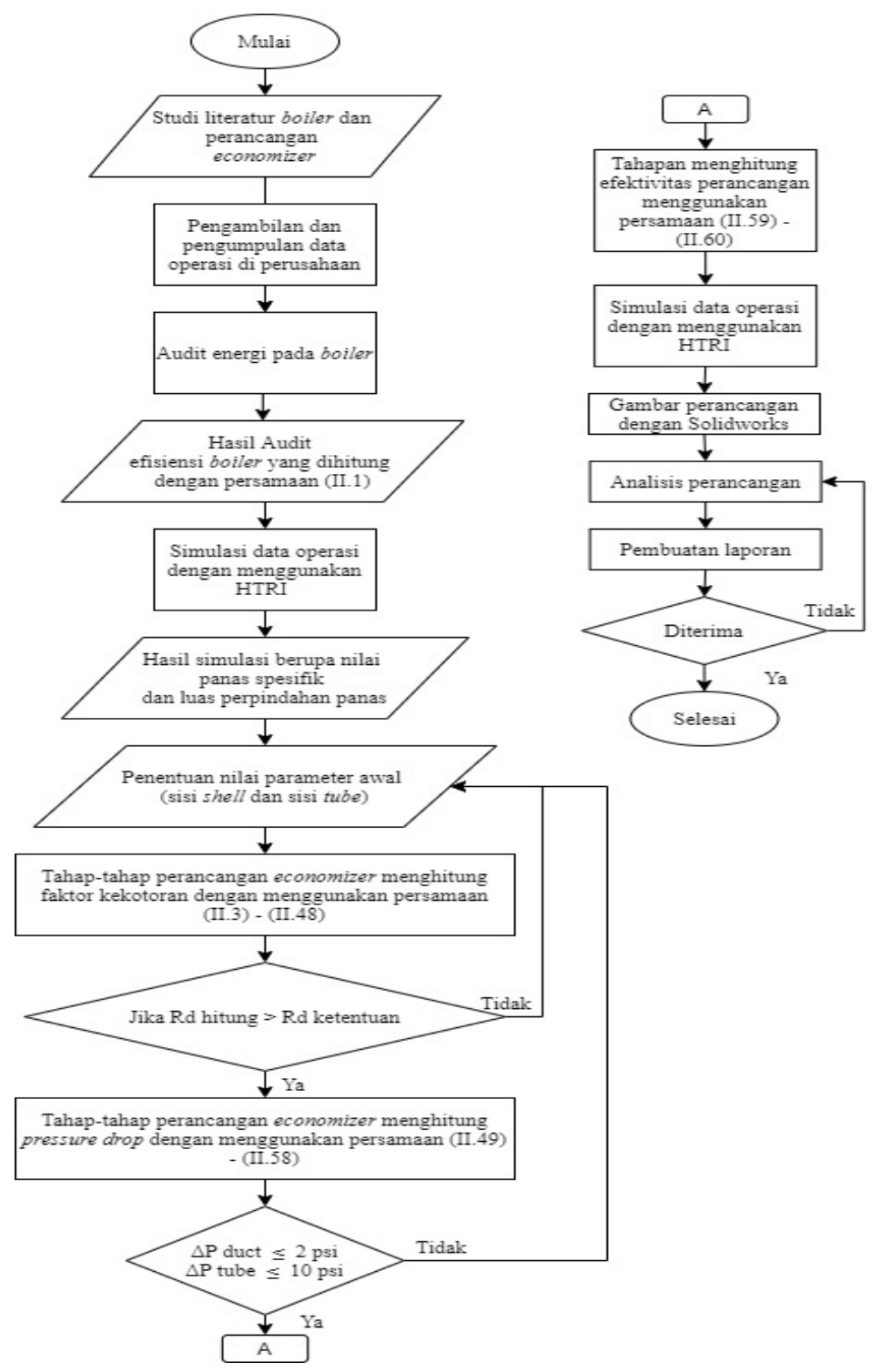

Gambar 2. Flowchart Tahapan Metode Penelitian

Sumber: Data primer yang diolah, Tahun 2020

\section{Kriteria Perancangan}

Kriteria perancangan economizer dibuat untuk menentukan target yang akan dicapai atau dicari untuk menyelesaikan penelitian yang dilakukan. Penyelesaian masalah penelitian ini dilakukan dengan metode kuantitatif. Metode kuantitatif tersebut antara lain:

1. perancangan economizer tipe helical fin and tube berdasarkan temperatur flue gas yang melebihi standarnya yaitu $250^{\circ} \mathrm{C}\left(482^{\circ} \mathrm{F}\right)$,

2. perancangan economizer tipe helical fin and tube mengikuti geometri sesuai dengan PT Pertamina (Persero) RU-VI Balongan,

3. melakukan analisis dari desain hasil perancangan. 
Tabel 1. Kriteria Perancangan

\begin{tabular}{lccc}
\hline \multicolumn{1}{c}{ Parameter } & Nilai & Satuan & Sumber \\
\hline Temperatur keluar feed & 284 & ${ }^{\circ} \mathrm{F}$ & PT Pertamina \\
water, $\mathrm{T}$ & & & \\
Temperatur flue gas, $\mathrm{T}$ & $>482$ & ${ }^{\circ} \mathrm{F}$ & Bhaskaran, 2016 \\
Tinggi economizer, $\mathrm{X}$ & 131.8872 & Inch & PT Pertamina \\
Lebar economizer, Y & 204.7344 & Inch & PT Pertamina \\
BWG & 18 & & PT Pertamina \\
Outside diameter tube & 1.5 & Inch & PT Pertamina \\
Bahan economizer & Carbon steel & & PT Pertamina \\
\hline
\end{tabular}

Sumber: Data primer yang diolah, Tahun 2020

\section{Persyaratan Perancangan}

Persyaratan perancangan digunakan merupakan tolak ukur dimana suatu perancangan diakatakan berhasil apabila telah memenuhi syarat-syarat yang telah ditentukan sebelumnya.

Tabel 2. Persyaratan Perancangan

\begin{tabular}{|c|c|c|c|}
\hline Parameter & Nilai & Satuan & Sumber \\
\hline $\begin{array}{l}\text { Faktor kekotoran (dirt } \\
\text { factor), Rd }\end{array}$ & $\geq 0.003$ & $\begin{array}{l}\text { jam. } \mathrm{ft}^{2} . \\
{ }^{\circ} \mathrm{F} / \mathrm{Btu}\end{array}$ & Kern, 1965 \\
\hline $\begin{array}{l}\text { Pressure drop sisi duct, } \\
\Delta \mathrm{P}\end{array}$ & $\leq 2$ & Psia & Kern, 1965 \\
\hline $\begin{array}{l}\text { Pressure drop sisi tube, } \\
\Delta \mathrm{P}\end{array}$ & $\leq 10$ & Psia & Kern, 1965 \\
\hline
\end{tabular}

Sumber: Data primer yang diolah, Tahun 2020

\section{Perhitungan Perancangan Economizer Tipe Helical Fin And Tube}

Persamaan perancangan economizer ini terdiri dari tiga tahap yaitu menghitung faktor kekotoran, menghitung beda tekanan di kedua sisi fluida, dan menentukan efektivitas perancangan. Persamaan perancangan yang digunakan berdasarkan buku Process Heat Transfer oleh Donald Q Kern tahun, 1965. 


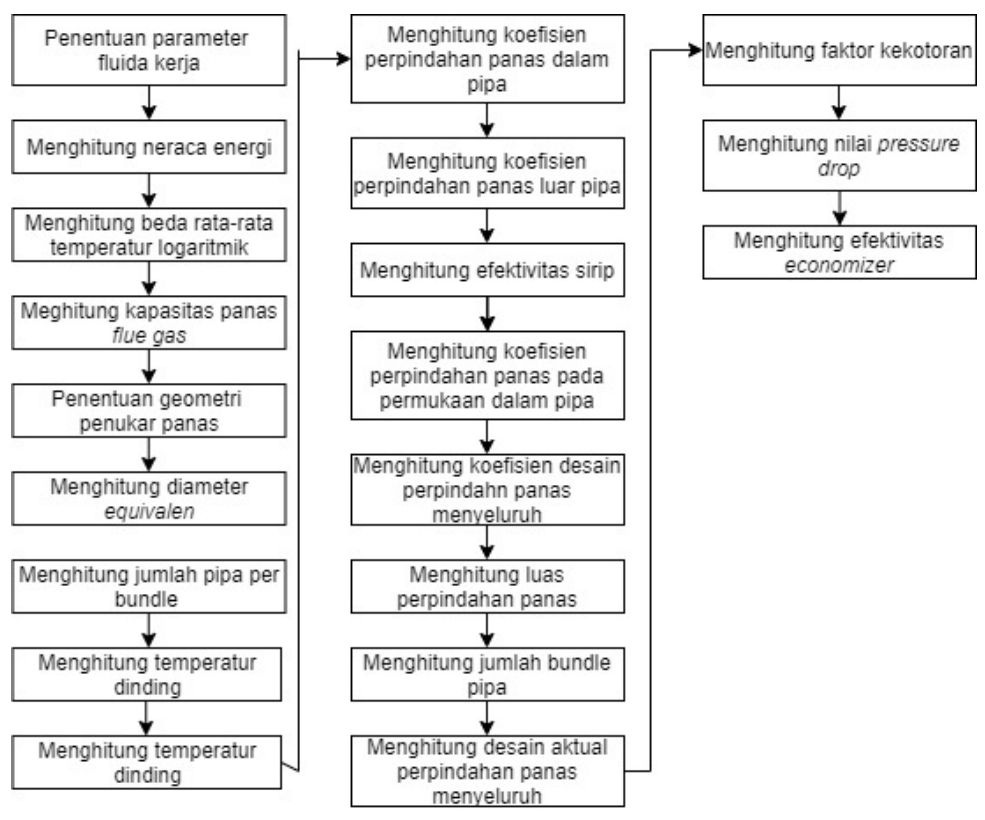

Gambar 3. Flowchart Tahapan Perhitungan Perancangan

Sumber: Data primer yang diolah, Tahun 2020

\section{HASIL DAN PEMBAHASAN}

Perancangan economizer menggunakan tipe helical fin and tube yang sebelumnya atau pada kondisi eksisting menggunakan tipe bare tube. Berikut ini adalah data proses perancangan dan data proses geometri yang digunakan untuk merancang economizer tipe helical fin and tube.

Tabel 3. Data Proses Perancangan

\begin{tabular}{|c|c|c|c|}
\hline No & Parameter & Nilai & Satuan \\
\hline 1 & Laju alir flue gas, W & 92643.59 & lb/jam \\
\hline 2 & Laju alir boiler feed water, $\mathrm{w}$ & 180690.1 & lb/jam \\
\hline 3 & Tekanan flue gas masuk, $\mathrm{P}_{\mathrm{h}, \text { in }}$ & 14.6 & Psia \\
\hline 4 & $\begin{array}{l}\text { Tekanan boiler feed water masuk, } \\
\mathrm{P}_{c, \text { in }}\end{array}$ & 377.3 & Psia \\
\hline 5 & Temperatur flue gas masuk $\mathrm{T}_{\mathrm{h}, \text { in }}$ & 654.404 & ${ }^{\circ} \mathrm{F}$ \\
\hline 6 & $\begin{array}{l}\text { Temperatur boiler feed water } \\
\text { masuk, } \mathrm{T}_{\mathrm{c}, \text { in }}\end{array}$ & 262.85 & ${ }^{\circ} \mathrm{F}$ \\
\hline 7 & Temperatur flue gas keluar, $\mathrm{T}_{\mathrm{h} \text {, out }}$ & 496.01 & ${ }^{\circ} \mathrm{F}$ \\
\hline 8 & $\begin{array}{l}\text { Temperatur boiler feed water } \\
\text { keluar, } \mathrm{T}_{\mathrm{c}, \text { out }}\end{array}$ & 284 & ${ }^{\circ} \mathrm{F}$ \\
\hline 9 & Kapasitas panas flue gas, $\mathrm{Cp}_{\mathrm{h}}$ & 0.285237 & $\mathrm{Btu} / \mathrm{lb} .^{\circ} \mathrm{F}$ \\
\hline 10 & $\begin{array}{l}\text { Kapasitas panas boiler feed water, } \\
C \mathrm{p}_{\mathrm{c}}\end{array}$ & 1.022729 & $\mathrm{Btu} / \mathrm{lb} .^{\circ} \mathrm{F}$ \\
\hline
\end{tabular}




\begin{tabular}{clcl}
\hline No & \multicolumn{1}{c}{ Parameter } & Nilai & \multicolumn{1}{c}{ Satuan } \\
\hline 11 & Konduktivitas termal flue gas, $\mathrm{k}_{\mathrm{h}}$ & 0.130196 & Btu/jam.ft. ${ }^{\circ} \mathrm{F}$ \\
12 & $\begin{array}{l}\text { Konduktivitas termal boiler feed } \\
\text { water, } \mathrm{k}_{\mathrm{c}}\end{array}$ & 0.395 & Btu/jam.ft. ${ }^{\circ} \mathrm{F}$ \\
13 & Viskositas flue gas, $\mu_{\mathrm{h}}$ & 0.36784 & $1 \mathrm{bm} / \mathrm{ft} . \mathrm{s}$ \\
14 & Viskositas boiler feed water, $\mu_{\mathrm{c}}$ & $1.429 \times 10^{-6}$ & $\mathrm{lbm} / \mathrm{ft} . \mathrm{s}$ \\
15 & Massa jenis boiler feed water, $\rho_{\mathrm{c}}$ & 57.96715 & $1 \mathrm{bm} / \mathrm{ft}^{3}$ \\
16 & Konduktivitas termal bahan, $\mathrm{kf}$ & 29.2768 & Btu/jam.ft. ${ }^{\circ} \mathrm{F}$ \\
\hline
\end{tabular}

Sumber: Data primer yang diolah, Tahun 2020

Tabel 4. Data Geometri Perancangan

\begin{tabular}{clcl}
\hline No & \multicolumn{1}{c}{ Parameter } & Nilai & \multicolumn{1}{c}{ Satuan } \\
\hline 1 & BWG & 18 & \\
2 & Diameter luar, OD & 1.5 & inch \\
3 & Diameter dalam, ID & 1.4 & inch \\
4 & Tebal pipa TD & 0.049 & inch \\
5 & Jarak antar ujung fin & 0.5 & inch \\
6 & Flow area per tube, a't & 1.54 & inch $^{2}$ \\
7 & Surface per lin ft outside & 0.3925 & $\mathrm{ft}^{2}$ \\
8 & Surface per lin ft inside, $\mathrm{A}_{\mathrm{i}}$ & 0.367 & $\mathrm{ft}^{2}$ \\
9 & Weight per lin ft & 0.831 & $\mathrm{lb} \mathrm{steel}_{1}$ \\
10 & Susunan pipa & staggered & \\
11 & Tinggi fin, 1 & 0.87 & inch \\
12 & Tebal fin, y & 0.05 & inch \\
13 & Jumlah fin per inch, N & 2 & \\
14 & Diameter luar dan fin, OD' & 2.37 & inch \\
15 & Panjang pipa, L & 8.68 & $\mathrm{ft}$ \\
16 & Tinggi duct, X & 131.8872 & inch \\
17 & Lebar duct, Y & 204.7244 & inch \\
\hline
\end{tabular}

Sumber: Data primer yang diolah, Tahun 2020

\section{Analisis Audit Energi}

Tujuan dari audit energi yaitu agar mengetahui efisiensi boiler di berbagai beban. Efisiensi tersebutlah yang akan menjadi acuan awal penggunaan data untuk perancangan economizer tipe helical fin and tube. Berdasarkan Gambar 4, efisiensi boiler terlihat fluktuasi dari tanggal 1 September 2020 sampai 19 September 2020. Hal ini disebabkan karena jumlah bahan bakar yang berperan sebagai energi input dan steam yang dihasilkan dari proses pemanasan berperan sebagai energi output berbeda-beda juga tiap waktunya. Rentang efisiensi boiler kapasitas 115 ton/h tersebut yaitu 93\% - 98\% dengan nilai terendah yaitu 
93.65\% pada tanggal 4 September 2020. Nilai efisiensi terendah tersebutlah yang akan dipakai sebagai acuan awal data untuk perancangan economizer tipe helical fin and tube. Penggunaan data boiler pada nilai efisiensi yang terendah bertujuan untuk mendapatkan nilai efektivitas perancangan economizer tipe helical fin and tube yang maksimal.

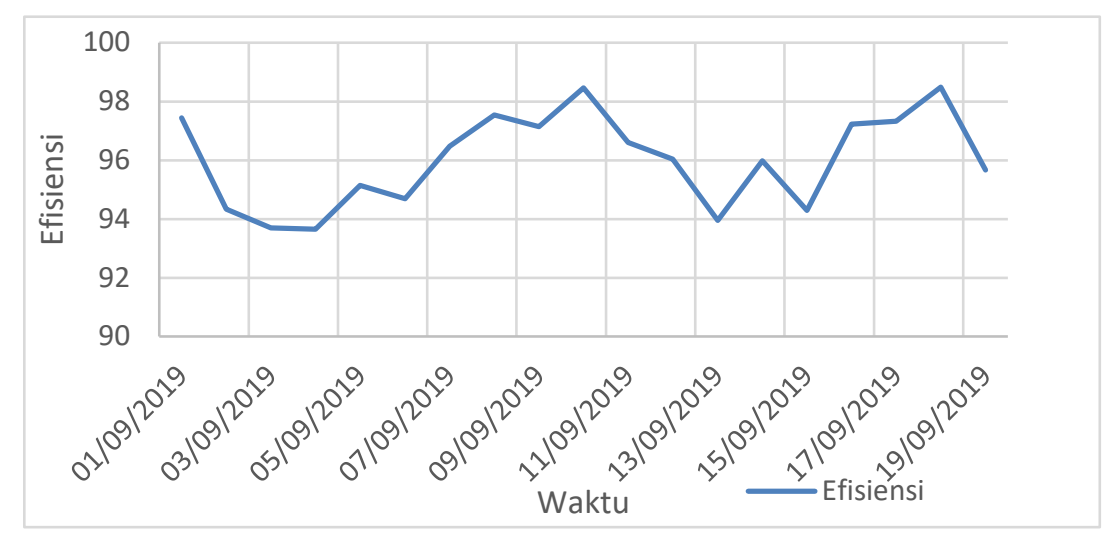

Gambar 4. Grafik Efisiensi Boiler

Sumber: Data primer yang diolah, Tahun 2020

\section{Analisis Perancangan Economizer}

Analisis perancangan economizer tipe helical fin and tube ini dapat ditinjau dari hasil perhitungan perancangan apakah hasil perancangan tersebut sudah memenuhi persyaratan perancangan yang sebelumnya telah ditentukan, yaitu persyaratan mengenai dirt factor $(\mathrm{Rd})$ dan pressure drop (penurunan tekanan). Nilai dirt factor perancangan economizer ini memiliki syarat harus lebih besar atau sama dengan nilai dirt factor ketentuan dengan nilai sebesar 0.003 jam. $\mathrm{ft}^{2} .{ }^{\circ} \mathrm{F} /$ Btu yang didapatkan dari tabel fouling factor (Kern, 1965). Nilai dirt factor dibutuhkan karena nilai faktor kekotoran mempengaruhi luas perpindahan panas pada alat penukar kalor. Alat penukar kalor harus mampu memindahkan panas sesuai kebutuhan proses dan ketentuan proses dalam kondisi terkotornya oleh karena itu nilai nya harus lebih besar dari dirt factor ketentuan. Jika nilai dirt factor perancangan lebih kecil dari dirt factor ketentuan akan menyebabkan tingginya biaya perawatan karena memiliki rentang waktu yang singkat. Pada persyaratan pressure drop, nilai pressure drop yang diperbolehkan untuk fluida cair yaitu sebesar 10 psi sehingga ini berlaku pada sisi tube sedangkan untuk fluida gas pressure drop yang diperbolehkan yaitu sebesar 2 psi berlaku pada sisi duct. 
Tabel 5. Hasil Perbandingan Perancangan

\begin{tabular}{lccc}
\hline \multicolumn{1}{c}{ Parameter } & Persyaratan & $\begin{array}{c}\text { Nilai } \\
\text { Perancangan }\end{array}$ & Satuan \\
\cline { 2 - 4 } & & 0.0077 & jam. $\mathrm{ft}^{2} .{ }^{\circ} \mathrm{F} / \mathrm{Btu}$ \\
\hline $\begin{array}{l}\text { Faktor kekotoran } \\
\text { (dirtfactor), Rd }\end{array}$ & 0.003 & $5.22779 \times 10^{-8}$ & Psi \\
$\begin{array}{l}\text { Pressure drop sisi } \\
\text { duct, } \Delta \mathrm{P}\end{array}$ & $<2$ & 3.7574 & Psi \\
$\begin{array}{l}\text { Pressure drop sisi } \\
\text { tube, } \Delta \mathrm{P}\end{array}$ & $<10$ & & \\
\hline
\end{tabular}

Sumber: Data primer yang diolah, Tahun 2020

Tabel 5 menunjukan perbandingan antara nilai perhitungan perancangan dan nilai persyaratan perancangan economizer tipe helical fin and tube yang kedua syaratnya terpenuhi. Hal ini menunjukkan bahwa perancangan economizer tipe helical fin and tube sudah layak untuk di operasikan. Jika fouling factor hasil perancangan dibawah 0.003 maka keadaan economizer akan mudah kotor sehingga rentang waktu maintenance semakin singkat. Begitupun sebaliknya, jika fouling factor hasil perancangan lebih besar dari 0.003 maka economizer tidak mudah kotor sehingga rentang waktu maintenance lebih lama. Analisis Efektivitas Economizer

Perhitungan efektivitas adalah salah satu cara yang digunakan untuk mengevaluasi kinerja dari sebuah economizer. Efektivitas juga digunakan untuk mengetahui seberapa besar kalor yang dilepaskan oleh flue gas yang dapat termanfaatkan untuk menaikan temperatur feed water. Metode perhitungan efektivitas ini menggunakan metode Number of Transfer Unit (NTU) baik sebelum perancangan dan sesudah perancangan.

Pada Gambar 5 menunjukan perbandingan efektivitas eksisting economizer dengan efektivitas perancangan economizer. Efektivitas eksisting atau sebelum dilakukan perancangan yaitu sebesar 0.243 dan efektivitas setelah dilakukan perancangan meningkat menjadi 0.402 .

Semakin tinggi nilai efektivitas dari economizer maka pemanasan feed water oleh flue gas semakin merata. Sedangkan, nilai efektivitas yang kecil dapat disebabkan karena tidak optimal penyerapan panas flue gas oleh feed water. Oleh karena adanya fungsi helical fin pada bagian tube nya untuk memperluas bidang penyerapan panas. 


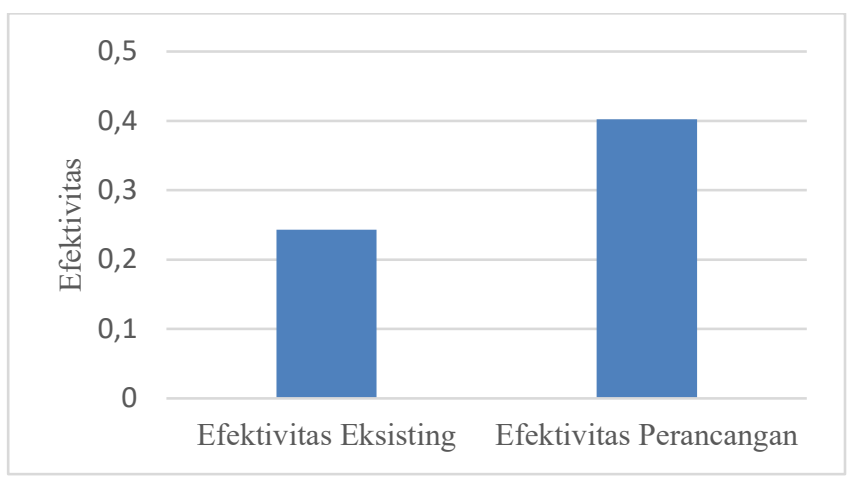

Gambar 5. Diagram Perbandingan Efektivitas Eksisting dan Perancang Sumber: Data primer yang diolah, Tahun 2020

\section{Analisis Penghematan Energi}

Kebutuhan energi maksimum yang digunakan untuk memanaskan feed water dari flue gas berbeda pada keadaan eksisting dan keadaan setelah perancangan. Besarnya penghematan energi bahan bakar merupakan selisih dari kalor pemanasan maksimum pada keadaan eksisting dan kalor pemanasan maksimum pada keadaan setelah perancangan.

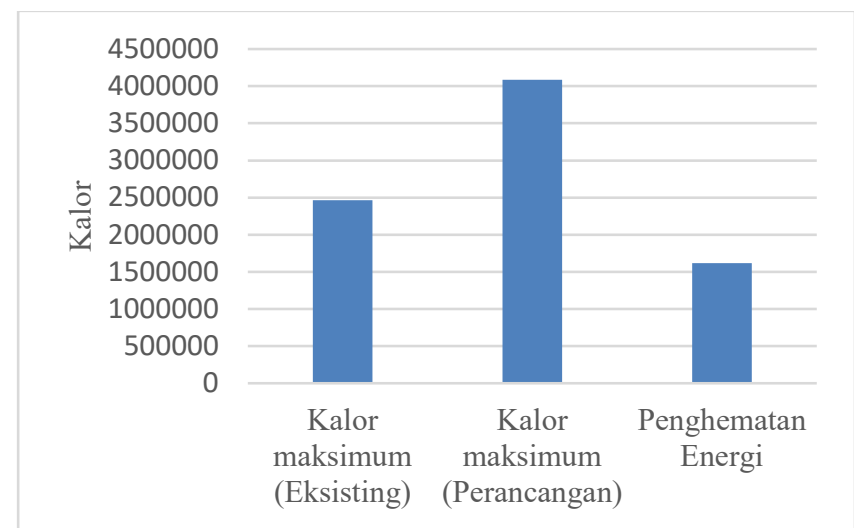

Gambar 6. Diagram Perbandingan Penghematan Energi Bahan Bakar Sumber: Data primer yang diolah, Tahun 2020

Flue gas yang digunakan sebagai pemanasa feed water berasal dari hasil pembakaran dua jenis bahan bakar yaitu natural gas dan solar. Untuk mengetahui penghematan energi bahan bakar dari masing masing bahan bakar perlu adanya perbandingan antara natural gas dan solar yang digunakan. Untuk natural gas digunakan sebanyak 67\% dan solar sebesar $33 \%$. Angka tersebut berupa asumsi perhitungan yang didapatkan dari tabulasi data. Sehingga didapatkan jumlah penghematan energi bahan bakar natural gas sebesar 1092088.844 Btu/jam dan solar sebesar 527109.0887 Btu/jam. Dengan membagi 
penghematan energi kedua bahan bakar dengan masing-masing nilai HHV nya maka didapatkan jumlah penghematan bahan bakar dalam satuan laju alir. Untuk natural gas sebesar $54.83 \mathrm{lb} / \mathrm{jam}$ dan untuk solar sebesar $27.025 \mathrm{lb} / \mathrm{jam}$.

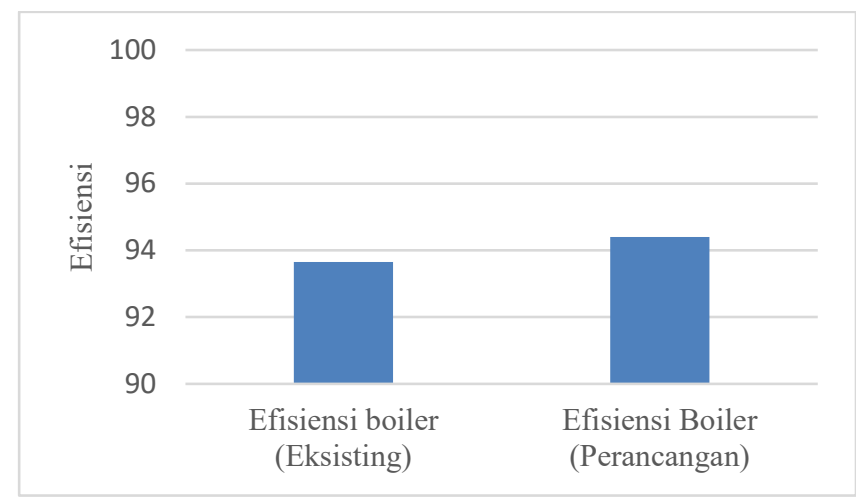

Gambar 7. Diagram Perbandingan Efisiensi Boiler

Sumber: Data primer yang diolah, Tahun 2020

Efisiensi boiler pada keadaan eksisting yaitu sebesari 93.65\%. Nilai efisiensi tersebut dapat ditingkatkan karena menurut data desain perusahaan idealnya berada 95\%. Setelah dilakukan perancangan dihasilkan efisiensi boiler meningkat dari sebelumnya yaitu sebesari $94.4 \%$.

\section{KESIMPULAN}

Dari hasil perancangan economizer tipe helical fin and tube, maka didapatkan kesimpulan bahwa hasil perancangan economizer dengan menambahkan helical fin pada bagian tube mampu menaikan nilai efektivitas economizer dari 0.2343 menjadi 0.402. Begitu pun dengan peluang penghematan bahan bakar setelah dilakukan perancangan economizer tipe helical fin and tube yaitu untuk natural gas sebesar $54.83 \mathrm{lb} / \mathrm{jam}$ dan solar sebesar $27.025 \mathrm{lb} / \mathrm{jam}$. Adanya penghematan bahan bakar boiler berdampak pada efisiensi boiler setelah dilakukan perancangan economizer tipe helical fin and tube yaitu sebesar $94.4 \%$. Sehingga hasil perancangan layak diimplementasikan berdasarkan analisis kelayakan secara teknik karena memenuhi kriteria perancangan dan syarat perancangan, 


\section{DAFTAR PUSTAKA}

Bhaskaran, Hari. (2016). Influence of Flue Gas and Feed Water Temperatures on Boiler Efficiency - An Analysis. International Journal of Innovative Research in Science, Engineering and Technology Vol. 5

Hendri, Suhengki, \& Panji Ramdhan. (2017). Analisa Efisiensi Boiler dengan Metode Heat Loss Sebelum dan Sesudah Overhaul PT. Indonesia Power UBP PLTU Unit 3. Jurnal Power Plant Vol. 4. 221-224.

Incropera, et. al. (Eds.). (2007). Introduction to Heat Transfer. New York, John Wiley and Sons (Asia) Pte Ltd.

Kementrian Energi dan Sumber Daya Mineral. (2019). Handbook of Energy \& Economic Statistics of Indonesia 2018. Jakarta: Kementrian Energi dan Sumber Daya Mineral.

Kern, Donal Q. (Eds.). (1965). Process Heat Transfer. New York, NY; McGraw-Hill Book Company Inc.

Muin, S. (Eds.). (1988). Pesawat-Pesawat Konversi Energi I (Ketel Uap). Indonesia, IDN: Rajawali.

Nugroho, Bagus Bayu, \& Sandy Novisa. (2019). Laporan Magang Industri PT Pertamina (Persero) RU-VI Balongan, Indramayu-Jawa Barat. Bandung: Jurusan Tekni Kimia, Politeknik Negeri Bandung.

Perry, H. Robert, \& Don W Green. (1984). Perry's Chemical Engineering Handbook $7^{\text {th }}$ Ed. USA: Mc Fraw Hill Comp.

Rayaprolu, K. (Eds.). (2009). Boiler for Power and Process. Boca Raton: CRC Press

Rayaprolu, K. (Eds.). (2013). Boiler A Practical Reference. Boca Raton: CRC Press.

Sarkar, D. (Eds.). (2015). Thermal Power Plant Design and Operation. United Kingdom, UK: Elsevier.

Smith, R. (Eds.). (2005). Chemical Process Design and Integration. United Kingdom, UK: John Wiley and Sons, Ltd.

Sullivan, W. G., et. al. (Eds.). (2015). Engineering Economy. Upper Saddle River: Pearson Higher Education.

The European Commission. (2015). How to Save Energy and Money in Boilers and Furnace System. Cape Town:The Energy Research Institute.

Thulukkanam, Kuppan. (Eds.). (2000). Heat Exchanger Design Handbook. Boca Raton: CRC Press Taylor \& Francis Group.

Wuryanti, Sri. (Eds.). (1995). Perpindahan Panas. Indonesia, IDN: Penerbit Pusat Pengembangan Pendidikan Politeknik. 